\title{
RNA interference targeting human integrin a6 suppresses the metastasis potential of hepatocellular carcinoma cells
}

\author{
Guannan Lv' ${ }^{1 \dagger}$, Tianjing Lv² , Shifeng Qiao', Wei Li', Weiran Gao ${ }^{1}$, Xiaohui Zhao ${ }^{1}$ and Jikun Wang ${ }^{1 *}$
}

\begin{abstract}
Background: Increased metastasis has been proved to be associated with a poor prognosis for hepatocellular carcinoma (HCC). There are higher-level expressions of integrin a6 in the tissues of HCC patients with a higher fatality rate. The aim of this study is to investigate the effect of short hairpin RNA (shRNA) silencing integrin a6 expression on the proliferation and metastasis in HCC cell lines.
\end{abstract}

Methods: Two human HCC cell lines, HepG2 and Bel-7402 were transfected with shRNA targeting human integrin a6. Protein and mRNA expression level were determined by western blot and real-time quantitative reverse transcription-polymerase chain reaction (qRT-PCR) to detect the transfected efficacy. The metastasis potential of HCC cells was evaluated by their proliferation, adhesion and invasion abilities. Cell proliferation was measured by MTT assay. Adhesion ability was measured by adhesion and spreading assays. The expression of matrix metalloproteinases (MMPs) was measured by qRT-PCR. The potential of invasion was measured by qRT-PCR and Transwell chamber assay. PI3K inhibitor LY294002 was used to explore the signal pathways of integrin a6 in HCC cells.

Results: Western blot and qRT-PCR detection showed that over 75\% of integrin a6 expression in HCC cells was through knockdown by shRNA. Proliferation, adhesion, spreading and invasion of HepG2 and Bel-7402 cells were dramatically decreased in cells transfected with shRNA compared to the control cells. P-ERK and p-AKT were reduced by shRNA targeting integrin a6 and PI3K inhibitor LY294002.

Conclusion: Knockdown integrin a6 can inhibit the proliferation and metastasis of HCC cells through PI3K/ARK and MAPK/ERK signal pathways by shRNA in vitro. Integrin a6 can mediate the metastasis potential, and can be used as a candidate target for therapy in HCC resulting in improved patients' survival.

Keywords: Hepatocellular carcinoma, integrin a6, Short hairpin RNA, Metastasis

\section{Background}

Hepatocellular carcinoma (HCC) is a highly lethal cancer with a poor prognosis. The occurrence of HCC has recently shown a worldwide increase [1], mainly because of its high metastasis potential [2].

Integrins are heterodimeric transmembrane receptors composed of non-covalently associated $\alpha$ and $\beta$ subunits. At least $18 \alpha$ and $8 \beta$ subunits have been identified so far, generating more than 24 members of the integrin family. Increasing evidence suggests that integrins are

\footnotetext{
* Correspondence: jikungwang@hotmail.com

${ }^{\dagger}$ Equal contributors

${ }^{1}$ The First Affiliated Hospital of Liaoning Medical College, Jinzhou 121001, China

Full list of author information is available at the end of the article
}

the most important receptors for cell metastasis [3]. Recently, it has been reported in many researches that integrin $\alpha 6 \beta 1$ and $\alpha 6 \beta 4$ were associated with metastasis of HCC $[4,5]$ and patients with high levels of expression of integrin $\alpha 6 \beta 1$ have a poorer prognosis $[4,6]$. Higher levels of expression of integrin $\alpha 6 \beta 4$ in patients is associated with increased invasive potential of $\mathrm{HCC}$, as well as a higher fatality rate [5,7]. Integrin $\alpha 6 \beta 1$, as an important kind of cell surface receptor, can mediate the adhesion between HCC cells and extracellular matrix (ECM) $[8,9]$. Owens et al. [10] demonstrates that integrin $\alpha 6 \beta 4$ could regulate the migration and invasion of laminin (LN) to stimulate the metastasis potential of HCC.

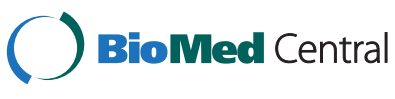

(c) 2013 Lu et al.; licensee BioMed Central Ltd. This is an Open Access article distributed under the terms of the Creative Commons Attribution License (http://creativecommons.org/licenses/by/2.0), which permits unrestricted use, distribution, and reproduction in any medium, provided the original work is properly cited. The Creative Commons Public Domain Dedication waiver (http://creativecommons.org/publicdomain/zero/1.0/) applies to the data made available in this article, unless otherwise stated. 
However, few research studies have focused on the single action of integrin $\alpha 6$ alone in the progression of HCC metastasis. Furthermore, the metastatic mechanisms under high levels of expression of integrin $\alpha 6$ are still unclear. A better understanding of the molecular mechanisms underlying integrin $\alpha 6$ affecting HCC metastasis may facilitate the development of targeted therapy.

In the current study, in order to explore the effect of integrin $\alpha 6$ in the process of HCC metastasis without the influence of $\beta$ subunits and the molecular mechanisms involved, two human HCC cell line, HepG2 and Bel-7402 were transfected with short hairpin RNA (shRNA) targeting human integrin $\alpha 6$. The metastasis potential of HCC cells was evaluated by proliferation, adhesion and invasion abilities. PI3K inhibitor LY294002 was also used to explore the signal pathway of integrin $\alpha 6$ in HCC cells.

\section{Methods}

\section{Cell culture and plasmids preparation}

Two hepatocellular cell lines, HepG2 and Bel-7402 were purchased from the Chinese Academy of Medical Science (Beijing, China). All cells were cultured in RPMI 1640 (Life Technologies Corporation, 5791 Van Allen Way, Carlsbad, CA 92008, US) with 10\% FBS, $200 \mu \mathrm{g} / \mathrm{ml}$ penicillin and streptomycin at $37^{\circ} \mathrm{C}$ in $5 \% \mathrm{CO}_{2}$. Integrin a6 shRNA plasmids (sc-43129-sh) were constructed and synthesized by Santa Cruz Biotechnology, Inc., CA, USA. Plasmids containing puromycin resistance genes were used for the selection of cells stably expressing shRNA. Control shRNA plasmids (sc-108065), each encoding a scrambled shRNA sequence that will not lead to the specific degradation of any known cellular mRNA, were also purchased from Santa Cruz Biotechnology, Inc., CA, USA.

\section{Cell transfection and clone selection}

Integrin $\alpha 6$ shRNA plasmids or control shRNA plasmids were transfected into HepG2 and Bel-7402 cells respectively, according to the manufacturer's instructions with slight modification. Briefly, in a 24-well tissue culture plate, cells were grown to approaching up to $85 \%$ to $90 \%$ confluence in RPMI 1640 with 10\% FBS. The medium was aspirated 24 hours before transfection, and replaced with DMEM. Lipofectamine 2000 (Invitrogen, Carlsbad, CA, USA) $0.5 \mu \mathrm{l}$ and plasmids $0.02 \mu \mathrm{g}$ were added in each well and incubated for six hours. After that, cells were cultured in RPMI 1640 with 20\% FBS, $400 \mu \mathrm{g} / \mathrm{ml}$ penicillin and streptomycin for 18 hours. After replacing the media with fresh normal growth medium, cells were incubated for an additional 24 hours. Three days later, stable transfectant clones were isolated with $1.6 \mu \mathrm{g} / \mathrm{ml}$ and $2 \mu \mathrm{g} / \mathrm{ml}$ puromycin (Santa Cruz Biotechnology, Inc., CA, USA) in HepG2 and Bel-7402 respectively.

\section{RNA extraction and qRT-PCR assays}

Briefly, $2 \mu \mathrm{g}$ total RNA was used to synthesize firststrand cDNA. Amplification and detection were performed using the ABI Prism 7500 Fast Real-time System (Applied Biosystems, Foster City, California, USA) starting with $1 \mu \mathrm{l}$ cDNA and TransStart Top Green qPCR SuperMix (TransGen Biotech, Beijing, China). Glyceraldehyde 3-phosphate dehydrogenase (GAPDH) was used as internal standard.

Primers sequences for integrin $\alpha 6$, matrix metalloproteinase (MMP)-2, MMP-9 and GAPDH were as follows:

$$
\begin{gathered}
\text { Integrin } \alpha 6: \text { 5'-TCCCTGAACCTAACGGAGT-3' and } \\
\text { 5'-ATGTCCAAGTAGTTC AGTT-3'; } \\
\text { MMPs-2: 5'-GCGACAAGAAGTATGGCTT-3' and } \\
\text { 5'-TGCCAAGGTCAATGT CAGG-3'; } \\
\text { MMPs-9: 5'-AGTTCCCGGAGTGAGTTGA-3' and } \\
\text { 5'-CTCCACTCCTCCCTT TCCT-3'; } \\
\text { GAPDH: 5'-GGCATCCTGGGCTACACTG-3' and } \\
\text { 5'-GTGGTCGTTGAGGGCAATG-3'. }
\end{gathered}
$$

The relative expression of integrin $\alpha 6$, MMP- 2 and MMP-9 mRNA was analyzed by the comparative cycle threshold $(\mathrm{Ct})$ method. All experiments were performed in triplicate.

\section{Western blot assays}

Cells $\left(1 \times 10^{6}\right)$ were washed with PBS twice and lysed with $1 \mathrm{ml}$ RIPA lysis buffer supplemented with $40 \mathrm{mmol} / \mathrm{L} \quad \mathrm{NaF}, 100 \mu \mathrm{mol} / \mathrm{L} \quad \mathrm{Na}_{3} \mathrm{VO}_{4}$, and $1 \mu \mathrm{l}$ Complete Protease Inhibitor (KeyGen Biotech Co. Ltd, Nanjing, China) for 30 minutes on ice. After removing the insoluble material by $12,000 \times \mathrm{g}$ centrifugation for 30 minutes at $4^{\circ} \mathrm{C}$, the supernatants were collected, boiled in $1 \times$ sodium dodecyl sulfate sample buffer for five minutes. Subsequent immunoblots were probed with the appropriate antibody and detected by Gel Imaging System G: BOX (Gene Company Limited, Cambridge, UK). Monoclonal rabbit anti-human CD49f (1:100, Abgent, San Diego, CA, USA), rabbit anti-human AKT (1:200); rabbit anti-human p-AKT (1:200); rabbit anti-human ERK (1:200); and rabbit anti-human p-ERK (1:200); antibody (these last four supplied by Santa Cruz Biotechnology, Inc., CA, USA), were used to detect the expression of integrin $\alpha 6, \mathrm{AKT}, \mathrm{p}-\mathrm{AKT}, \mathrm{ERK}$, and p-ERK respectively. GAPDH (1:500; Santa Cruz Biotechnology, Inc., CA, USA) was used as internal control.

\section{Cell proliferation assays}

Cell proliferation was determined by MTT assay in accordance with other studies [11]. Briefly, $2 \mu \mathrm{g} / \mathrm{cm}^{2}$ of LN 
(Sigma, St. Louis, MO, USA) was placed on a ten-dish plate and allowed to solidify at $37^{\circ} \mathrm{C}$ for two hours. The other wells were coated with $2 \mu \mathrm{g} / \mathrm{cm}^{2}$ of fibronectin (FN) (Sigma, St. Louis, MO, USA) as control. After washing each well twice with PBS, $8 \times 10^{3}$ cells were incubated in 96-well plates with DMEM containing $10 \%$ FBS at $37^{\circ} \mathrm{C}$ in $5 \% \mathrm{CO}_{2}$ for 48 hours. MTT $(10 \mu \mathrm{l})$ was added to each well and four hours later, the media was aspirated and $100 \mu$ limethyl sulfoxide (DMSO) was added. The assay was quantified in a Multimode Microplate Reader-Varioskan Flash (Thermo Electron Corporation, Waltham, MA, USA) at $490 \mathrm{~nm}$. All experiments were repeated in at least quadruplicate.

\section{In vitro adhesion assay}

LN or FN was coated in 96-well plates according to the method described above [12]. In total, $8 \times 10^{3}$ cells suspended in DMEM were cultured at $37^{\circ} \mathrm{C}$ in $5 \% \mathrm{CO}_{2}$ for 30 minutes. After being washed with DMEM three times, acid phosphatase substrate consisting of $0.1 \mathrm{~mol} / \mathrm{l}$ sodium acetate buffer ( $\mathrm{pH} 5.5), 0.1 \%$ Triton X-100 (10 mmol/L), and nitrophenylphosphate $100 \mu \mathrm{l}$ were added to each well. The cells were cultured at $37^{\circ} \mathrm{C}$ for two hours, then $1 \mathrm{~mol} /$ $\mathrm{L} \mathrm{NaOH} 10 \mu \mathrm{l}$ was added to each well to stop the reaction. The adhesion assay was quantified in a Multimode Microplate Reader-Varioskan Flash (Thermo, Electron Corporation, Waltham, MA, USA) at $405 \mathrm{~nm}$. All the results were obtained from at least three independent experiments.

\section{In vitro spreading assay}

LN was coated in 96-well plates according to the method described above. In total, $8 \times 10^{3}$ cells suspended in DMEM were cultured at $37^{\circ} \mathrm{C}$ at $5 \% \mathrm{CO}_{2}$ for 150 minutes. Then, a light microscope $(\times 200)$ was used to determine the spreading assay. In this experiment, spreading cells were counted respectively in three distinct visions.

\section{LN invasion assay}

The upper part of the Transwell chambers coated with LN was used as a basement membrane (BM) according to the way described above. Fibronectin (FN) was used as control. Cells $\left(1 \times 10^{5}\right)$ suspended in DMEM containing $0.1 \%$ FBS were plated in the upper part to make contact with the BM. BSA (0.05\%) in DMEM with $10 \%$ FBS was placed in the lower chamber, to act as chemoattractants. Cell invasion was determined by crystal violet dissolution assay after incubation at $37^{\circ} \mathrm{C}$ in $5 \% \mathrm{CO}_{2}$ for 48 hours; the invaded cells were numerated under a light microscope $(\times 400)$. In this experiment, invaded cells were counted in three distinct microscopic fields respectively.

\section{The signal pathways assay}

LN or FN was coated in 24-well plates according to the method described above. Cells $\left(1.5 \times 10^{6}\right)$, serum-starved for 48 hours, were allowed to adhere to the LN or FN and incubated at $37^{\circ} \mathrm{C}$ in $5 \% \mathrm{CO}_{2}$ for two hours. In order to demonstrate the PI3K/AKT and MAPK/ERK signal pathways, which are necessary for the reaction between HCC cells and LN, PI3K inhibitor LY294002 was used one hour before HepG2 cells were cultured in plates coated with $2 \mu \mathrm{g} / \mathrm{cm}^{2}$ of LN. DMSO was used as control. Protein and mRNA were extracted and analyzed as described in the western blot assay and real-time quantitative reverse transcription-polymerase chain reaction (qRT-PCR) assay.

\section{Statistical analysis}

Statistical analysis was performed with SPSS 15.0 for Windows (Chicago, IL, USA). Values are expressed as the mean \pm standard deviation. The student $t$-test was used for comparison between groups. $P<0.05$ was considered statistically significant.

\section{Results}

The stable transfection of integrin a6-shRNA plasmid dramatically down-regulated the expression of integrin a6

As shown in Figure 1, in the western blot assay, compared with the control group, the protein grayscale value of integrin $\alpha 6$ reduced remarkably in the HepG2shRNA-integrin $\alpha 6$ cells (Figure 1A). In the qRT-PCR assays, compared with the control group, the relative integrin $\alpha 6$ mRNA reduced remarkably $(P<0.05)$ (Figure 1B). About $75 \%$ of integrin $\alpha 6$ was from knockdown by shRNA. The same result can be found in Bel7402 cells $(P<0.001)$.

The results demonstrated that the expression level of integrin $\alpha 6$ was dramatically down-regulated after stable transfection at both protein and RNA level with significant statistical difference.

\section{Lower integrin a6 expression caused decreased proliferation of HCC cells on LN}

As shown in Figure 2, a lower level of integrin $\alpha 6$ caused decreased proliferation of HCC cells on LN. This suggested that the proliferation of HCC cells was associated with the expression level of integrin $\alpha 6$ reacting with LN.

\section{Lower integrin a6 expression caused decreased invasion potential of HCC cells}

To specifically address the importance role of integrin a6 in the invasion of HCC cells, we performed the Transwell experiments coated with LN or FN. We found that cells expressing lower-level integrin $\alpha 6$ showed a lower invasion potential (Figure 3). A total of $91.0 \pm 1.33$ HepG2-control shRNA cells crossing LN, compared to $8.67 \pm 1.56$ in the HepG2-integrin $\alpha 6$ shRNA cells $(P<$ 0.0001 ) (Figure 3D). Furthermore, the number of HepG2-control shRNA cells crossing FN $(75.0 \pm 2.67)$ was significantly less than the cells crossing $\mathrm{LN}(P=$ 


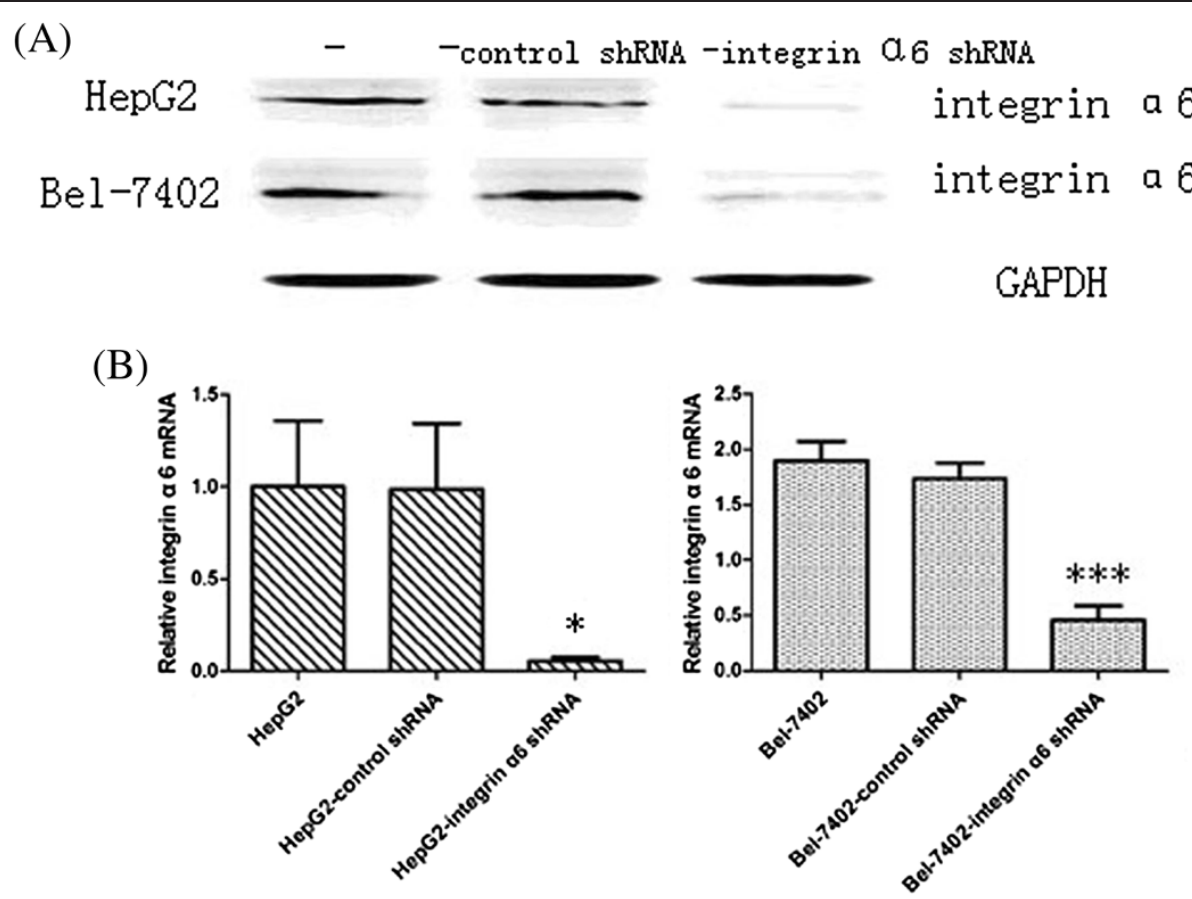

Figure 1 HepG2 and Bel-7402 cells were infected with integrin a6 short hairpin RNA (shRNA) plasmids and control shRNA plasmids respectively. Stable transfectant clones were picked up by puromycin. Integrin a6 expression levels remarkably reduced. (A) Western blot assays yielded the expression level of integrin a6 on protein level in HepG2 and Bel-7402 cell lines. (B) The qRT-PCR assays showed the expression level of integrin a6 on mRNA level in HepG2 and Bel-7402 cell lines. ${ }^{*} P<0.05 ;{ }^{* * *} P<0.001$ compared with control group.

0.0034) (Figure 3D). These results indicated that lowerlevel expression of integrin $\alpha 6$ caused decreased invasion potential for HCC cells, and LN can increase invasion potential of HCC cells with high integrin $\alpha 6$ levels.

Lower integrin $a 6$ expression reduced invasion potential of HCC cells through the down-regulation of adhesion ability, spreading ability and secretion of MMPs

It has been mentioned above that adhesion and spreading is the first step of the model for tumor metastasis reported by Liotta et al., so we performed adhesion and spreading assays in vitro. These yielded results showing that the adhesion ability reduced remarkably in the HCC cells with lower-level expression of integrin $\alpha 6(P<0.0001)$ (Figure 4A). On spreading, the results showed that HepG2 cells with lower level of integrin $\alpha 6$ had a lower rate of spreading (2.4\% in the HepG2-shRNA-integrin $\alpha 6$ and $94 \%$ in the HepG2) (Figure 4B). The qRT-PCR assay was used to detect the relative integrin MMP-2 and MMP-9 levels. Compared with control group, the relative MMP-2 and MMP-9 mRNA reduced remarkably $(P<0.01)$ (Figure $4 C, D)$. Thus, the down-regulation of MMP-2 and MMP-9 secretion, adhesion and spreading ability may cause the low invasion potential of HCC cells.
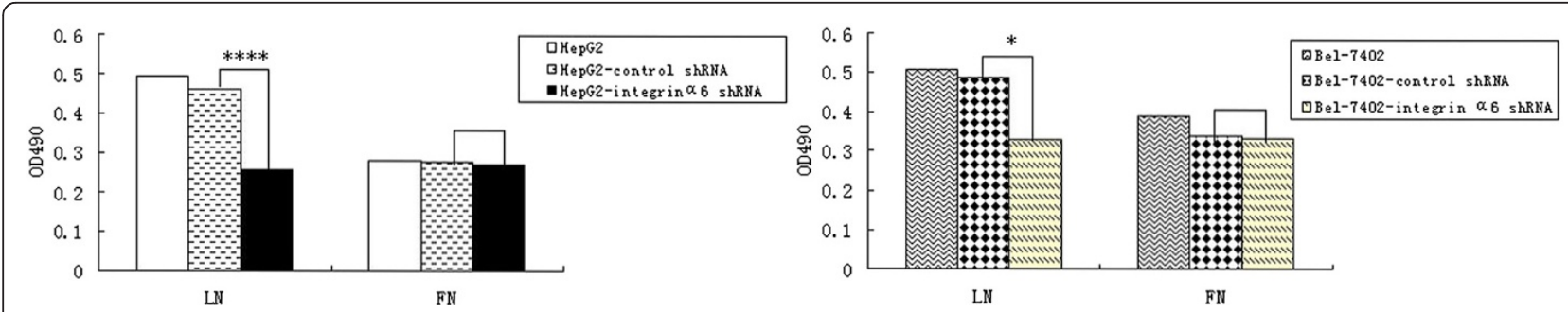

Figure 2 Cells were incubated in $\mathbf{9 6 - w e l l ~ p l a t e s ~ c o a t e d ~ w i t h ~ l a m i n i n ~ ( L N ) ~ o r ~ f i b r o n e c t i n ~ ( F N ) ~ r e s p e c t i v e l y ~ f o r ~} \mathbf{4 8}$ hours. The MTT assays showed that the lower-level expression of integrin a6 caused decreased proliferation of HCC cells with significant statistical difference $(P<0.05)$ in the cells incubated on LN, while the cells incubated on FN did not show any statistically significant effect $(P>0.05)$. ${ }^{*} P<0.05,{ }^{* * * *} P<0.0001$ compared with control group. 


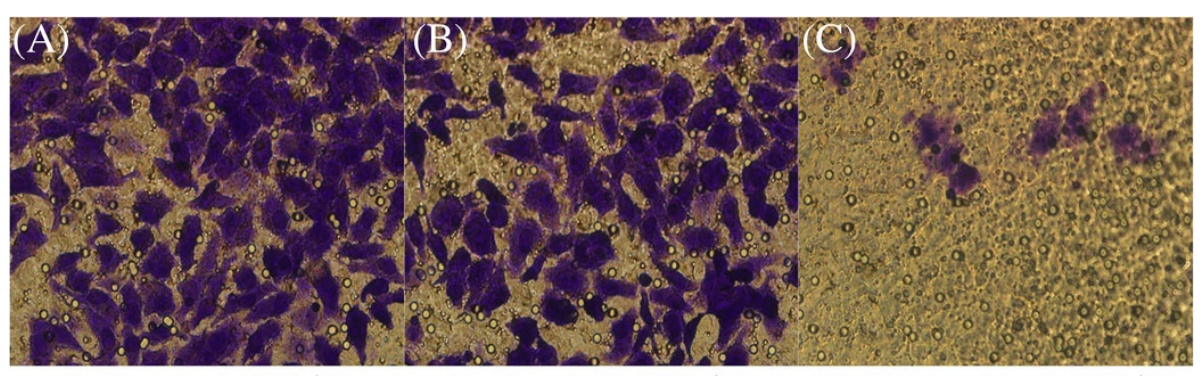

HepG2-control shRNA/LN

HepG2-control shRNA /FN

HepG2-integrin a 6 shRNA/LN

Figure 3 Cells were cultured in Transwell chambers with the upper part coated with laminin (LN) or fibronectin (FN) respectively for 48 hours. The invaded cells were numerated under a light microscope ( $\times 400)$. (A) HepG2 infected by control shRNA plasmids invaded LN. (B) HepG2 cells infected by control shRNA plasmids invaded FN. (C) HepG2 cells infected by integrin a6 shRNA plasmids invaded LN. HepG2 had a decreased invasion potential after the knockdown of integrin a6 with significant statistical difference $(P<0.0001)$. It also proved that $L N$ can increase invasion potential of HepG2 $(P<0.05)$.

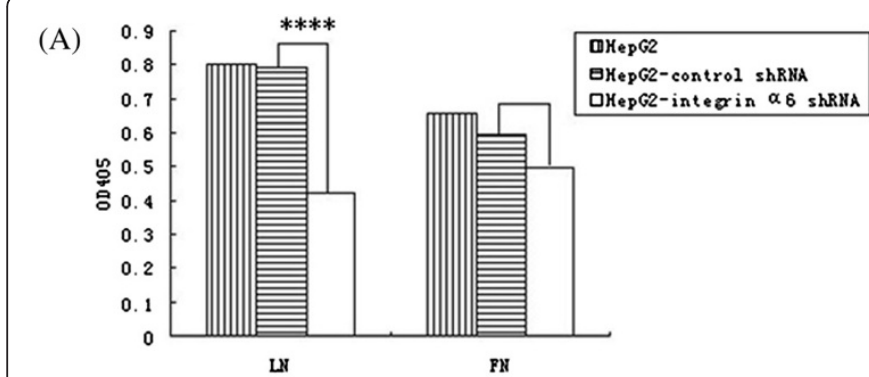

(B)

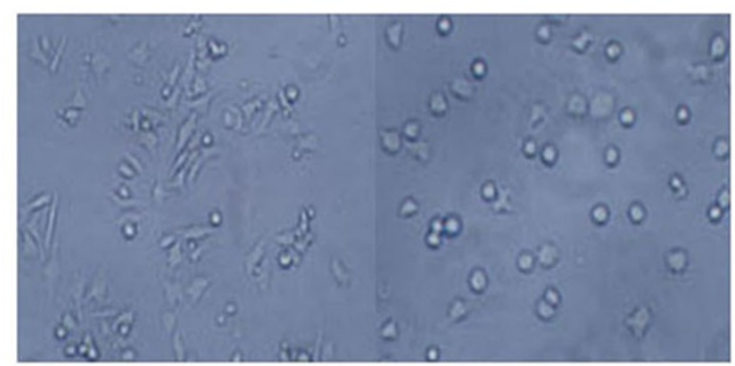

HepG2-control shRNA

HepG2-integrin a 6 shRNA

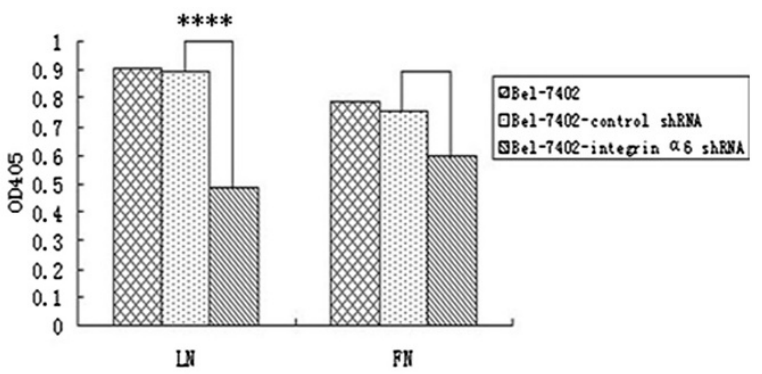

(C)

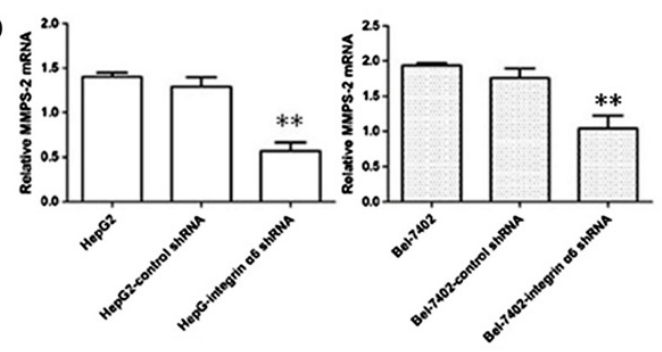

(D)

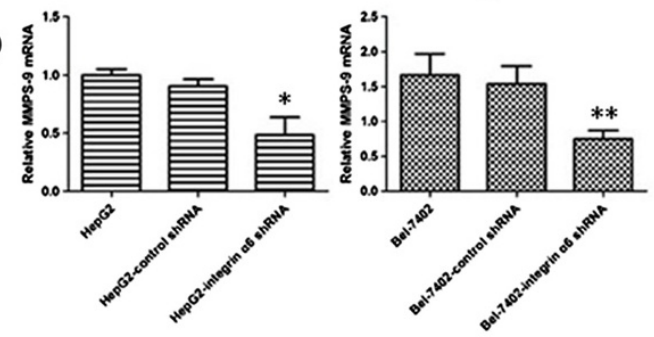

Figure 4 Cells were cultured in 96-well plates coated with laminin (LN) or fibronectin (FN) respectively for 30 minutes and then cultured with acid phosphatase substrate at $37^{\circ} \mathrm{C}$. The reaction was stopped two hours later. (A) The adhesion assays showed that lowerlevel integrin a6 reduced the adhesion of HCC cells with significantly statistical difference $(P<0.0001)$ in the cells incubated with $L N$, while the cells incubated with FN did not show any significant effect $(P>0.05)$. (B) Cells cultured in 96-well plates were coated with LN for 150 minutes. The spreading cells were numerated under a light microscope (X200). HepG2 cells with lower level of integrin a6 had a lower spreading rate. (C) The qRT-PCR assay showed that MMP-2 expression reduced significantly at mRNA level $(P<0.01)$. (D) The qRT-PCR assay showed that MMP-9 expression reduced significantly at RNA level $(P<0.01)$. ${ }^{*} P<0.05$, ${ }^{* *} P<0.01$, ${ }^{* * *} P<0.0001$ compared with control. 
Integrin a6 reacting with $L N$ induced the hyperactivation of PI3K/AKT and MAPK/ERK signal pathways

As shown in Figure 5, compared with the control group, the protein grayscale value of p-ERK, p-AKT was dramatically reduced in HepG2 cells transfected with integrin $\alpha 6$ shRNA plasmids compared with control shRNA plasmids (Figure 5A, B). As revealed in Figure 5C, LY294002 decreased both the expression of p-ERK and p-AKT, but had no influence on the expression of ERK and AKT. The proliferation of HepG2 cells was remarkably decreased after being inhibited by PI3K $(P<0.05)$ (Figure 5D). In Transwell assays, $38.33 \pm 3.78$ cells crossed LN in the HepG2/LY294002 group, while $64.0 \pm$ 2.67 cells in the HepG2/DMSO group and $72.33 \pm 3.11$ cells in HepG2 group $(P<0.05)$ (Figure $5 \mathrm{E})$ crossed LN. These results demonstrated that the reacting of integrin $\alpha 6$ with LN induced the hyperactivation of PI3K/AKT and MAPK/ERK signal pathways.

\section{Discussion}

Metastatic recurrence is the main obstacle to the improvement of treatment efficacy for HCC [13], and heterodimeric transmembrane protein generated by integrin $\alpha 6$ subunits is suggested to be associated with metastasis potential of HCC. In this study, we used LN, the important structural component of ECM and integrin $\alpha 6$ ligand, as a model molecule and applied several assays to determine the importance of integrin $\alpha 6$ in the metastasis of HCC cells. In order to make the results more objective, the integrin $\alpha 6$ shRNA was used to silence the expression of integrin $\alpha 6$ of two HCC cell lines at RNA level. Western blot and qRT-PCR detection showed that over $75 \%$ of integrin $\alpha 6$ expression in HCC cells was through knockdown by shRNA.

Tumor metastasis is a multi-step process involving various molecules, pathways and organs. This process mainly includes the following steps before invasion to

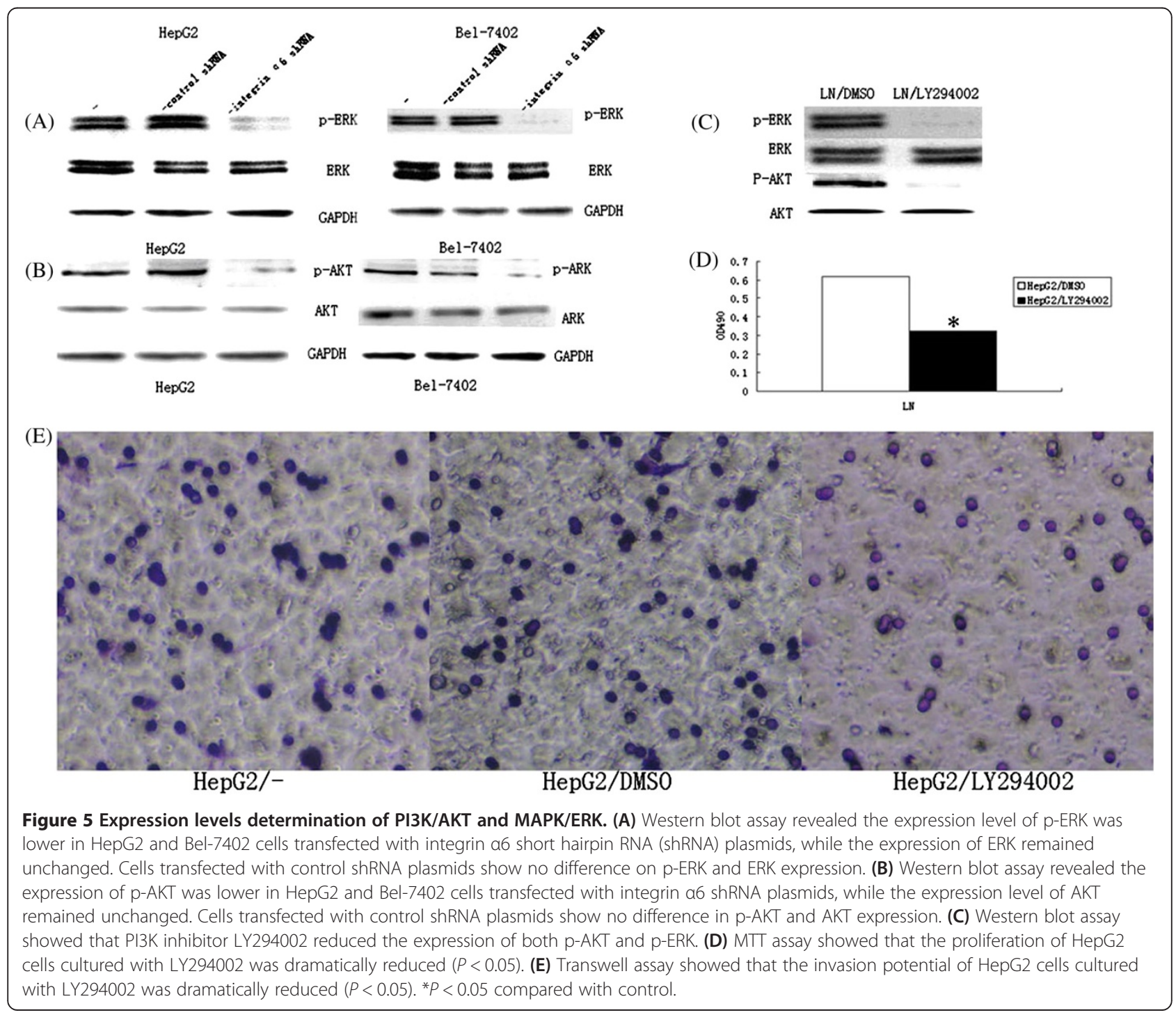


form micrometastases in the metastatic site: the detachment of tumor cells from a primary tumor, invasion through the stromal tissues, intravasation into the blood/lymph vessels, arrest in capillary bed followed by extravasation and local crawling [14].

Based on the results of our assays, lower-level integrin $\alpha 6$ expression down-regulated the secretion of matrix metalloproteinases (MMPs), the adhesion force between HCC cells and LN, the spreading ability on the LN, as well as the invasion potential of HCC cells. p-ERK and p-AKT were reduced by shRNA targeting integrin $\alpha 6$ and PI3K inhibitor LY294002. LN could stimulate the MMPs secreted by HCC and thus was associated with a more metastatic phenotype of HCC cells [15]. The phosphorylation level of ERK and AKT (p-ERK and p-AKT), which has been reported to be increased after combining integrin $\alpha 6$ with LN [16,17], is associated with a low survival rate for $\mathrm{HCC}$ patients [17]. Furthermore, influencing factors increase the secretion of MMP-9 through the activation of the MAPK/ERK signal pathway, which is conducive with HCC metastasis [18]. The same results have been found in the PI3K/AKT signal by Chen et al. [19].

A model for tumor metastasis reported by Liotta et al. [20] in the early 1980 s contributes in large part to the metastatic process. The model mentions that there are three stages for the complicated interactions between tumor cells and ECM: the adhesion of tumor cells to the ECM, secretion of proteolytic enzymes, such as MMPs, directly by the tumor cells or indirectly by the host cells as a response to the presence of tumor cells, and finally, cell movement by chemotaxis or haptotaxis. Although most integrin family members recognize more than one ECM protein, integrin $\alpha 6$ is a ligand with specificity for LN $[21,22]$. The signal pathways, MAPK/ERK and PI3K/ AKT have been proved to be necessary for HCC metastasis $[19,23]$. Thus, we can hypothesize that the combination of integrin $\alpha 6$ with LN could influence the HCC metastasis by affecting cell adhesion and migration, and reduced expression level of integrin $\alpha 6$ may cause low potential of $\mathrm{HCC}$ metastasis through the activation of MAPK/ERK and PI3K/AKT signal pathways. There also exist cross-talk between the two signaling pathways activated by $\mathrm{LN}[18,19]$. Integrin $\alpha 6$ contributes to the regulation of interaction between HCC cells and LN through PI3K/AKT and MAPK/ERK signaling pathways which are shown to be essential for the metastasis of HCC [6].

\section{Conclusions}

Down-regulation of integrin $\alpha 6$ could decrease the potential of $\mathrm{HCC}$ metastasis through reducing the interaction between HCC and LN. This study showed that over-expression of integrin $\alpha 6$ in $\mathrm{HCC}$ is a strong indicator for more aggressive tumors and poorer clinical outcome. All the currently available therapies for HCC are mainly oriented towards removing or destroying the tumors, whereas few therapies aim at blocking the process of HCC metastasis [24]. This study would help us to understand the metastatic process of HCC better and develop targeted molecular therapy to improve patients' survival.

\section{Abbreviations}

HCC: Hepatocellular carcinoma; shRNA: Short hairpin RNA; qRT-PCR: Real-time quantitative reverse transcription-polymerase chain reaction; MMPs: Matrix metalloproteinases; ECM: Extracellular matrix; LN: Laminin; Ct: Cycle threshold; DMSO: Dimethyl sulfoxide; FN: Fibronectin.

\section{Competing interests}

The authors declare that they have no competing interests.

\section{Authors' contributions}

GNL conducted experiments, prepared manuscript and analyzed data. TJLand SFQ performed experiments, revised manuscript and analyzed data. WL performed experiments. WRG performed experiments. XHZ erformed experiments. JKW designed experiments and gave final approval of manuscript. All authors read and approved the final manuscript.

\section{Acknowledgement}

This project was supported by the Department of Education, Liaoning Province, China (L2010288).

\section{Author details}

${ }^{1}$ The First Affiliated Hospital of Liaoning Medical College, Jinzhou 121001, China. ${ }^{2}$ Institute of Urology, Peking University First Hospital, Peking University, Beijing 100034, China.

Received: 25 September 2013 Accepted: 14 November 2013 Published: 4 December 2013

\section{References}

1. Sengupta B, ASiddiqi S: Hepatocellular carcinoma: important biomarkers and their significance in molecular diagnostics and therapy. Curr Med Chem 2012, 19:3722-3729.

2. Zhu K, Dai Z, Pan Q, Wang Z, Yang G-H, Yu L, Ding Z-B, Shi G-M, Ke A-W, Yang X-R: Metadherin promotes hepatocellular carcinoma metastasis through induction of epithelial-mesenchymal transition. Clin Cancer Res 2011, 17:7294-7302.

3. Desgrosellier JS, Cheresh DA: Integrins in cancer: biological implications and therapeutic opportunities. Nat Rev Cancer 2010, 10:9-22.

4. Fei Y, Wang J, Liu W, Zuo H, Qin J, Wang D, Zeng H, Liu Z: CD151 promotes cancer cell metastasis via integrins alpha3beta1 and alpha6beta1 in vitro. Mol Med Rep 2012, 6:1226-1230.

5. Stipp CS: Laminin-binding integrins and their tetraspanin partners as potential antimetastatic targets. Expert Rev Mol Med 2010, 12:e3.

6. Ke AW, Shi GM, Zhou J, Huang XY, Shi YH, Ding ZB, Wang XY, Devbhandari RP, Fan J: CD151 amplifies signaling by integrin a6 $\beta 1$ to PI3K and induces the epithelial-mesenchymal transition in HCC Cells. Gastroenterology 2011, 140:1629-1641. e1615.

7. Choi YP, Kim BG, Gao M-Q, Kang S, Cho NH: Targeting ILK and $\beta 4$ integrin abrogates the invasive potential of ovarian cancer. Biochem Biophys Res Commun 2012, 427:642-648.

8. Fu B-H, Wu Z-Z, Qin J: Effects of integrin a $6 \beta 1$ on migration of hepatocellular carcinoma cells. Mol Biol Rep 2011, 38:3271-3276.

9. Carloni V, Mazzocca A, Pantaleo P, Cordella C, Laffi G, Gentilini P: The integrin, alpha6beta1, is necessary for the matrix-dependent activation of FAK and MAP kinase and the migration of human hepatocarcinoma cells. Hepatology 2001, 34:42-49.

10. Owens DM, Romero MR, Gardner C, Watt FM: Suprabasal alpha6beta4 integrin expression in epidermis results in enhanced tumorigenesis and disruption of TGFbeta signaling. J Cell Sci 2003, 116:3783-3791.

11. Bergamini C, Sgarra C, Trerotoli P, Lupo L, Azzariti A, Antonaci S, Giannelli G: Laminin-5 stimulates hepatocellular carcinoma growth through a 
different function of a6 $\beta 4$ and a3 $\beta 1$ integrins. Hepatology 2007, 46:1801-1809.

12. Lu T, Zhang Q, Zhou R: Laminin and its alpha 6 integrin receptor in the regulation of human hepatocellular carcinoma cell phenotypes. Zhonghua Zhong Liu Za Zhi 2003, 25:31-35.

13. Ding S-J, Li Y, Tan Y-X, Jiang M-R, Tian B, Liu Y-K, Shao X-X, Ye S-L, Wu J-R, Zeng $R$ : From proteomic analysis to clinical significance overexpression of cytokeratin 19 correlates with hepatocellular carcinoma metastasis. Mol Cell Proteomics 2004, 3:73-81.

14. Geho DH, Bandle RW, Clair T, Liotta LA: Physiological mechanisms of tumor-cell invasion and migration. Physiology 2005, 20:194-200.

15. Giannelli G, Fransvea E, Bergamini C, Marinosci F, Antonaci S: Laminin-5 chains are expressed differentially in metastatic and nonmetastatic hepatocellular carcinoma. Clin Cancer Res 2003, 9:3684-3691.

16. Givant-Horwitz V, Davidson B, Reich R: Laminin-induced signaling in tumor cells. Cancer Lett 2005, 223:1-10.

17. Schmitz KJ, Wohlschlaeger J, Lang H, Sotiropoulos GC, Malago M, Steveling K, Reis H, Cicinnati VR, Schmid KW, Baba HA: Activation of the ERK and AKT signaling pathway predicts poor prognosis in hepatocellular carcinoma and ERK activation in cancer tissue is associated with hepatitis C virus infection. J Hepatol 2008, 48:83-90.

18. Weng C-J, Chau C-F, Hsieh Y-S, Yang S-F, Yen G-C: Lucidenic acid inhibits PMA-induced invasion of human hepatoma cells through inactivating MAPK/ERK signal transduction pathway and reducing binding activities of NF-KB and AP-1. Carcinogenesis 2008, 29:147-156.

19. Chen J, Wang Q, Fu X, Huang XH, Chen X, Cao L, Chen L, Tan H, Li W, Bi J: Involvement of PI3K/PTEN/AKT/mTOR pathway in invasion and metastasis in hepatocellular carcinoma: association with MMP-9. Hepatol Res 2009, 39:177-186.

20. Pauli BU, Schwartz DE, Thonar EJ-M, Kuettner KE: Tumor invasion and host extracellular matrix. Cancer Metastasis Rev 1983, 2:129-152

21. Humphries JD, Byron A, Humphries MJ: Integrin ligands at a glance. J Cell Sci 2006, 119:3901-3903.

22. Morgan MR, Humphries MJ, Bass MD: Synergistic control of cell adhesion by integrins and syndecans. Nat Rev Mol Cell Biol 2007, 8:957-969.

23. Huynh H, Nguyen TTT, Chow K-HP, Tan PH, Soo KC, Tran E: Over-expression of the mitogen-activated protein kinase (MAPK) kinase (MEK)-MAPK in hepatocellular carcinoma: its role in tumor progression and apoptosis. BMC Gastroenterol 2003, 3:19.

24. Arosio D, Casagrande C, Manzoni L: Integrin-mediated drug delivery in cancer and cardiovascular diseases with peptide-functionalized nanoparticles. Curr Med Chem 2012, 19:3128-3151.

doi:10.1186/2047-783X-18-52

Cite this article as: Lv et al:: RNA interference targeting human integrin a6 suppresses the metastasis potential of hepatocellular carcinoma cells. European Journal of Medical Research 2013 18:52.

\section{Submit your next manuscript to BioMed Central and take full advantage of:}

- Convenient online submission

- Thorough peer review

- No space constraints or color figure charges

- Immediate publication on acceptance

- Inclusion in PubMed, CAS, Scopus and Google Scholar

- Research which is freely available for redistribution

Submit your manuscript at www.biomedcentral.com/submit
( Biomed Central 